\title{
PELOS CAMINHOS DA JUDICIALIZAÇÃO: LEI, DENÚNCIA E PROTEÇÃO NO CONTEMPORÂNEO
}

\author{
Maria Livia do Nascimento ${ }^{1}$ \\ Universidade Federal Fluminense, Niterói-RJ, Brasil
}

\begin{abstract}
RESUMO. Ao se colocarem em análise os processos de judicialização serão problematizadas verdades instituídas sobre lei, denúncia, proteção, justiça, segurança e vigilância. Em particular, será contextualizada a chamada proteção à infância e à adolescência, uma vez que a denúncia é tomada como um modo de participação, de responsabilidade social e condição para a realização da justiça. A proposta é, então, pensar a denúncia como um modo de produção de verdade, e os movimentos dessa prática, que em defesa da lei faz funcionar a máquina do judiciário por seus canais institucionalizados, como por exemplo o da denúncia anônima. Desse modo, vão se organizando redes de vigilância que acionam o judiciário, apoiando as políticas de judicialização, e ao mesmo tempo criminalizam e moralizam as famílias ao colocarem sob suspeição seus modos de vida. Por esse percurso, a dinâmica da denúncia tem como objetivo fazer uso de uma legislação punitiva para regular os cotidianos familiares, colocando em funcionamento uma estreita relação entre lei, ordem e proteção.

Palavras-chave: Leis; processos legais; Foucault, M.
\end{abstract}

\section{UPON THE PATHWAYS OF JUDICIALIZATION: LAW, DENOUNCEMENT AND PROTECTION IN THE CONTEMPORARY}

\begin{abstract}
By putting in analysis the judicialization process, truths established about law, denouncement, protection, justice, violence and vigilance will be problematized. In particular, the so called childhood and adolescence protection, taken as a way of participation, social responsibility and a condition for the realization of justice, which will be contextualized in view of encouraging the denouncement. Therefore, the proposal is to think the denouncement as a way of producing truths, and the movements of this practice that makes the machine of the judiciary works, through its institutionalized channels, like the anonymous denouncement for example. Thus, vigilance networks that trigger the judiciary start to be organized, supporting judicialization policies while criminalizing and moralizing the families when putting under suspicion their ways of life. Through this course, the dynamics of the denouncement aims to make use of a punitive legislation in order to regulate the everyday familiar practices, producing a close relationship among law, order and protection.
\end{abstract}

Keywords: Laws; legal processes; Foucault, M.

\section{POR LOS CAMINOS DE LA JUDICIALIZACIÓN: LEY, DENUNCIA Y PROTECCIÓN EN EL CONTEMPORÂNEO}

RESUMEN. Al colocar en análisis los procesos de judicialización, serán problematizadas verdades instituidas sobre ley, denuncia, protección, justicia, seguridad y vigilancia. Específicamente será contextualizada la llamada protección a la infancia y la adolescencia, con énfasis en el incentivo a la denuncia, como un modo de participación, de responsabilidad social y condición para la realización de la justicia. La propuesta es entonces, pensar la denuncia como una forma de producción de verdad y los movimientos de esa práctica, que en defensa de la ley coloca a funcionar la maquina judiciaria por canales ya institucionalizados, por citar un ejemplo, la denuncia anónima. De esta forma van accionándose redes de vigilancia que accionan el terreno de lo judicial, apoyando las políticas de judicialización, al mismo tiempo que criminalizando y moralizando las familias, al colocar sobre sospecha sus formas de vida. Por esos caminos, la dinámica de la denuncia tiene como objetivo, hacer uso de una legislación punitiva para regular la vida cotidiana de las familias, colocando en funcionamiento una estrecha relación entre ley, orden y protección.

Palabras-clave: Leyes; processos legales; Foucault, M.

1 Endereço para correspondência: Rua João Pessoa 154/403 - CEP 24.220-331 - Niterói-RJ, Brasil. E-mail: mlivianascimento@gmail.com. 
É instigante discutir a judicialização problematizando algumas verdades instituídas sobre lei, denúncia, proteção, justiça, segurança, vigilância, etc. São as relações que ocorrem entre esses domínios que afirmam os processos que chamamos judicialização da vida, entendida esta como uma construção subjetiva que implanta a lógica do julgamento, da punição, do uso da lei como parâmetro de organização da vida.

Vejamos uma dessas relações, aquela que se faz entre proteção, segurança e justiça. Nos tempos atuais se afirma um modo subjetivo: desejar proteção é desejar segurança e justiça, fabricação social e histórica que imprime à proteção a condição de ser intensamente desejada no presente. Tal desejo coloca a proteção como um bem absoluto e necessário, justificando toda e qualquer prática dita protetiva ao ser ela aliada à segurança. Foucault (2004/2008a) nos apresenta a sociedade de segurança como aquela na qual há um investimento na segurança como paradigma central de controle e de sustentação do sistema do capital contemporâneo.

Seguindo essa ordem de pensamento, tomo aqui a proteção como uma construção histórica, ou seja, como uma concepção associada a determinadas práticas/discursos, surgida em um dado período histórico e inserida em um determinado jogo de forças. Em minhas pesquisas na área da infância $e$ da adolescência, tenho trabalhado alguns temas, como assistência, infância, família, abandono e o modo como esses temas se apresentam nos documentos oficiais que tratam da chamada proteção para essa população. No transcorrer das análises que venho fazendo, busco as construções históricas e os efeitos que tais documentos produzem. As chamadas leis de proteção à infância e à adolescência estão se ampliando a cada momento. Além do Estatuto da Criança e do Adolescente temos a chamada Nova lei da adoção, o Plano Nacional de Promoção, Proteção e Defesa do direito de Crianças e Adolescentes à Convivência Familiar e Comunitária, as orientações técnicas do CONANDA (Conselho Nacional de Direitos da Criança e do Adolescente) e os planos de audiência concentrada destinados a definir a vida da infância abrigada. Essas leis, normativas, decretos e recomendações vão se estendendo a diferentes espaços e seus conteúdos são tomados como verdades absolutas, estáticas e fechadas, sendo formadores das práticas de proteção instituídas.

Esse conjunto de leis, envolto por uma capa muito bem ajustada dos discursos da proteção, visa regular a vida. É valioso pensar a emergência de tantas leis, mas seria restrito ficar apenas na análise do aumento da presença da lei na sociedade, sendo importante ultrapassar esse caráter inflacionário do surgimento de uma grande quantidade de leis. Seria preciso perguntar e discutir a emergência da crença na lei como solução para todo e qualquer conflito, de uma briga pessoal à superação da desigualdade social, trazendo a lógica do tribunal para praticamente todos os âmbitos da vida. Com essa análise, outra questão se coloca: como o direito e a justiça foram implantando práticas que conduzem o social, judicializando a vida? A hegemonia da lógica judiciária desconsidera outros modos de organização e concentra a ação na lei? Como foi se implantando essa subjetividade segundo a qual a lei vai tudo resolver? Como se constrói o olhar judicializante?

Foucault (2004/2008b) escreve que a justiça tende a ser um serviço público onipresente, uma vez que a lei vai se tornando cada vez mais formal. No entendimento do filósofo, a formalização da lei no sentido de sua promulgação, organização e constituição favorece a intervenção judiciária. O direito que culmina no século XXI é o da particularização, da fragmentação, porque se perde de vista a referência da luta política, social e popular, afirmando-se uma tradição jurídica legalista forte, que faz com que a lei tenha um peso enorme.

Nesse âmbito há um incentivo à denúncia, tomada como um modo de participação, de responsabilidade social e condição para a realização da justiça e das normas. Importante referir que no mundo da judicialização foi implantada a máxima "somos todos responsáveis", que delega às redes de proteção e a toda e qualquer pessoa os funcionamentos antes restritos aos operadores da justiça. Isto se deu quando a própria lei passou a conclamar à participação. A referência no âmbito da família, da criança e do adolescente é sempre o artigo 227 da Constituição Federal, que incita todos a participar, antes de recorrer à justiça:

É dever da família, da sociedade e do Estado assegurar à criança, ao adolescente e ao jovem, com absoluta 
prioridade, o direito à vida, à saúde, à alimentação, à educação, ao lazer, à profissionalização, à cultura, à dignidade, ao respeito, à liberdade e à convivência familiar e comunitária, além de colocá-los a salvo de toda forma de negligência, discriminação, exploração, violência, crueldade e opressão. (Brasil, 1988).

Por essa determinação legal, a justiça não deveria ser a única responsável por todos os problemas e conflitos, visto que a todos cabe um investimento na aplicação da lei.

Pela lógica menorista, baseada no Código de Menores, vigente no Brasil de 1927 a 1990, qualquer problema ligado à proteção da infância e da adolescência era conduzido ao Juizado de Menores. Com o Estatuto da Criança e do Adolescente (ECA), lei que passou a vigorar a partir de julho de 1990, institui-se a chamada rede de atendimento, que passou a contar com os conselhos tutelares, os Centros de Referência de Assistência Social (CRASs), as ONGs e outras organizações que devem ser procuradas antes que a justiça seja acionada. Nessa nova situação, todos têm que operar a partir da lei, o que amplia o poder judiciário, com base em uma estratégia que entende a proteção como maximização de controle biopolítico pelo dispositivo da segurança, conforme aponta Foucault (1997/2010) em seus escritos das décadas de 1970/1980, sobretudo em seu curso "Segurança, território e população". Para o autor, a biopolítica é um modo de governo da vida, uma ordem política baseada fundamentalmente nas ideias de gestão dos perigos e promoção da saúde dos seres vivos de uma população. Com esse referencial discute a maneira como o poder se modulou na passagem do século XVIII para o XIX. Naquela época emergiu um dispositivo de governo que atuava não somente nos indivíduos, pelo eixo das disciplinas, mas também como poder sobre a vida, na qual se deve investir através da sujeição dos corpos e da gestão calculada da população pelo cuidado político. É o biopoder, que para conhecer, organizar e controlar a vida, atua pelos dispositivos de segurança e se expande apregoando a saúde e a redução dos riscos.

Seguindo esse percurso, podemos pensar os funcionamentos da proteção, no campo aqui estudado como uma estratégia do biopoder, que atua tanto nas famílias em particular modelando seus corpos ou ao indicando como a mãe deve se comportar, por exemplo - quanto na população, já que, ao fazer determinações nos modos de viver, produz saberes que vão estabelecer estratégias de regulação sobre um conjunto maior de pessoas, sobre o corpo social.

A proteção é, assim, uma prática de governo biopolítico que controla as famílias pelos dispositivos da segurança e da prevenção. Tal compreensão bifurca os sentidos do que é estar protegido. Dentro dessa discussão é importante dizer que para Foucault (2004/2008a, 1994/2012a) as artes de governar não se dão apenas por coerção, há um encontro entre as maneiras pelas quais os indivíduos são dirigidos por outros e os modos como conduzem a si mesmos (técnicas de si).

As famílias atendidas pela chamada rede de proteção à infância e à adolescência são policiadas, vigiadas, ameaçadas, denunciadas e julgadas de maneira insistente por pessoas próximas - como vizinhos e familiares -, pelos professores de seus filhos, pelos especialistas dos sistemas de saúde e de assistência. Esse conjunto de situações expressa a cultura do castigo por meio da lógica penal, a judicialização da vida e o exercício da autoridade disseminada no social.

Nesse sentido, podemos pensar a denúncia como uma prática de produção de verdade que se apoia na defesa da lei, na necessidade de fazer funcionar a máquina do judiciário por meio de canais institucionalizados como, por exemplo, a denúncia anônima. A lógica é: quando denuncio uma família por negligência, por exemplo, estou participando, estou exercendo minha responsabilidade cidadã, estou evitando o perigo e fazendo algo justo ao cooperar com a justiça. Ao fazer a denúncia faço o bem, e não penso no que ocorrerá com a pessoa denunciada e os procedimentos que a atravessarão. Apenas acredito que a lei garantirá, como uma verdade, a minha proteção, a proteção coletiva e/ou a proteção de alguém que julgo estar em perigo. Aqui se concebem com essenciais o judiciário e a intervenção, possibilitando que a consciência cidadã possa dormir em paz. Desse modo, vão se organizando redes de vigilância que acionam o judiciário e apoiam as políticas de judicialização ao inculcarem o pensamento de que existe uma vida certa e o que a garantirá será o judiciário.

No presente artigo a proposta é pensar a judicialização pela prática da denúncia tomada 
como um instrumento de proteção; porém é preciso estabelecer um recorte, porque não se pode referir-se à denúncia como um todo, já que ela não tem uma essência que possibilite universalizar um discurso. Ela não é algo único, e para colocá-la em análise podemos percorrer diferentes caminhos, já que tem sentidos diversos. Enfim, há diferentes maneiras de incitar à denúncia, uma vez que ela pode ser compreendida de vários modos.

Diante disso, escolho fazer uma discussão sobre a denúncia a partir de alguns pontos de análise que se entrelaçam. Um deles diz respeito à crença na lei e na força da justiça, ambas claras vertentes da judicialização; outro se refere à denúncia como resposta a uma convocação à participação cidadã.

\section{POR AMOR À LEI PERMITIMOS A JUDICIALIZAÇÃO DA VIDA}

$\mathrm{O}$ ato de denunciar o outro às autoridades competentes, aos profissionais especializados, ao judiciário, na maioria das vezes de modo anônimo, ajusta-se com precisão ao jogo da judicialização, porque é visto como uma prática de defesa da lei, uma prática que sustenta uma moral de retidão, de justiça.

É por se acreditar na lei, por se temer a lei, que a justiça se torna a referência para atuar e passamos a ter uma institucionalização do judiciável, cuja função, além de determinar o que é lícito e o que é ilícito, é regular as funções do corpo social. Um bom exemplo é a judicialização do espaço escolar imposta por legislações referentes ao bullying, que pune o agressor por meios legais (abre processo judicial) ou dos regulamentos da escola (expulsar da escola), mas também produz a separação entre o que é normal e o que é anormal dentro dos estabelecimentos escolares, acreditando-se que ao fazer essa regulação, ao implantar essa dicotomia estarão resolvidas as questões, as tensões referentes às relações dentro da escola. O que vemos é um incremento das práticas judiciárias baseadas na lei. $\mathrm{E}$ por quê? De acordo com Foucault (1976/1988), porque a lei de fato funciona cada vez mais como uma norma que agencia a produção de condutas esperadas, ao mesmo tempo em que a instituição judiciária se integra cada vez mais como um aparelho cujas funções são essencialmente reguladoras. Para o filósofo,
... a lei tem portanto por papel e função é a própria operação da lei - codificar uma norma, efetuar em relação à norma uma codificação, ao passo que o problema que procuro identificar é mostrar como, a partir e abaixo, nas margens e talvez até mesmo na contramão de um sistema da lei se desenvolvem técnicas de normalização. (Foucault, 2004/2008a, p. 74).

As palavras de Foucault nos anunciam a sociedade da norma, que agencia a produção de condutas esperadas, o padrão, o comportamento que opera em função do modelo - um controle que se dá e se interioriza nas pessoas em função daquilo que elas deveriam ser. $\mathrm{Na}$ sociedade da norma há um critério de divisão dos indivíduos: o normal e o patológico. São designadas atitudes consideradas normais boas performances, que passam a servir de parâmetro de classificação das pessoas.

A denúncia anônima coloca o denunciante no lugar daquele que defende a justiça. Se queremos proteção, nada mais aceitável do que a justiça invadir nossas vidas, reprimindo os espaços considerados perigosos, violentos, que trazem o desequilíbrio da ordem. Denunciar é valorizar uma justiça funcional, que deve detectar o que é perigoso para a sociedade a fim de vigiar a população, é tentar enquadrar o denunciado no espaço de justiça para que seja julgado e receba o castigo merecido - afinal, é preciso defender a sociedade.

"Em defesa da sociedade" é o título de um curso de Foucault (1997/2010), ministrado em 1975-1976. Algumas das questões aqui delineadas se sustentam nos debates ocorridos nesse curso, porém tomo outra escolha bibliográfica para as discussões feitas aqui: um texto publicado em "Ditos e Escritos" que tem como título "A estratégia do contorno" (Foucault, 1994/2012a). É uma escrita que traz, de modo bem sucinto, as ideias amplamente apresentadas no curso referido. A narrativa se concentra em quatro pontos que me parecem destacados para as análises que viso empreender sobre a relação entre judicialização e proteção.

Diz o autor: "Defender a sociedade tornou-se um princípio funcional comum à polícia, aos procuradores, aos magistrados instrutores e aos juízes." (Foucault, 1994/2012a, p. 134). Na sequência, Foucault refere que eles se entendem porque jogam a mesma função, que penso ser a função punitiva baseada em uma 
norma comum, porque ditada por uma lei universal. Considero essa afirmação importante porque nos faz pensar a lógica punitiva que conduz as práticas desses profissionais, sempre pautadas por uma verdade que dizem aplicar-se igualmente para todos.

Em um segundo ponto Foucault assinala que há, sem dúvida, uma defesa contra infrações, mas que o objeto principal da defesa da sociedade são os perigos futuros; e pergunta: "Defender a sociedade contra o quê?" (Foucault, 1994/2012a, p. 135). Alega que por trás de fatos danosos como as infrações se desenha um perigo por vir. $\mathrm{O}$ desemprego é um perigo, mas a violência que ele pode produzir é que deve trazer preocupação. É um perigo porque afronta a ordem social que exige a inclusão no mundo do trabalho; mas deve preocupar principalmente porque produz revoltas, resistências, desordem urbana, crimes e infrações legais.

Outra pergunta resume o terceiro ponto: "Como se proteger?" (Foucault, 1994/2012a, p. 135). Buscando os autores da infração, se possível, mas tentar sanar as infrações não é o principal. Para ele, "a estratégia do contorno é mais eficaz: fazer medo, fazer exemplo, intimidar." (p. 135) - enfim, agir sobre a população virtualmente perigosa, agir sobre a população que um dia vai ocasionar problemas, por exemplo, os jovens desempregados.

Por fim mais uma pergunta: "O que é preciso proteger?" (Foucault, 1994/2012a, p. 135). Foucault vai dizer que é preciso proteger o que é mais precioso, mais necessário, mais ameaçado: o Estado, já que é ele que protege a sociedade. Assim, a função da justiça é proteger o Estado contra os perigos que o ameaçam. A lógica é proteger o Estado para que ele cumpra sua função de proteger a sociedade, o que ocorre por meio dos aparelhos da justiça. Com isso ele vai nos dizer que a justiça está bem assentada entre a sociedade e o Estado.

O levantamento desses quatro pontos aquece o debate sobre a proteção e traz a ideia de uma justiça funcional que deve detectar o que é perigoso para a sociedade a fim de vigiar a população. Ainda no texto, Foucault (1994/2012a) afirma que os imperativos do Estado são naturalizados, já que são impostos por meio das funções de proteção social. O que ele está querendo dizer com isso é que a proteção cria uma prática de consentimento, indivíduos do consentimento que aceitam a justiça de modo naturalizado. Assinala que há, sem dúvida, uma defesa contra infrações, mas que o objeto principal da defesa da sociedade são os perigos futuros.

\section{EU ME TORNO CIDADÃO QUANDO DENUNCIO}

Vivemos tempos em que há um investimento na lei como constituição da cidadania. Há uma construção social segundo a qual se terá o status de cidadão porque uma lei o protege. Assim, por exemplo, o Estatuto do Idoso traria cidadania para aqueles que por estarem em idade avançada precisam de proteção. Indo na mesma direção, o ECA se afirma como uma lei que institui a criança cidadã. A própria Constituição Federal de 1988 passou a ser apelidada de constituição cidadã por trazer os chamados direitos e garantias para as pessoas e os grupos. As leis estão aí mesmo para serem utilizadas com rigor, e em geral são vistas como poucas e insuficientes. A demanda é que outras sejam criadas. O clamor por leis mais duras e corretivas se justifica para evitar condutas consideradas danosas para a sociedade. Com isso se quer evitar que crianças levem palmadas (lei da palmada), que haja brigas na escola (lei do bullying), que mulheres sejam espancadas (lei Maria da Penha), dando à lei a função pedagógica de mudanças de comportamento, já que ela pretende obstruir determinadas condutas.

Há a ilusão de que a criação de uma lei muitas vezes demandada por movimentos sociais - vai resolver todos os problemas. Exemplos disto são o movimento feminista e a Lei Maria da Penha, que geraram uma prática penal associada a movimentos de vingança e ódios imensos. Outro são os movimentos LGBT, que também clamam pela criminalização da homofobia como dispositivo punitivo. É bom que não nos enganemos: essa demanda por leis que se pautam pelos discursos da proteção, da luta pela igualdade e da construção da cidadania visa também regular a vida, criminalizar culpados e punir.

Os fluxos nos levam para a demanda por mais leis e assim criam uma incapacidade de convivência, já que podemos depositar na lei e em seus procedimentos jurídicos a tarefa de tudo resolver. Com a lei ficam esvaziados os canais de sociabilidade e de comunicação, os espaços públicos de investimento. A solução do problema se faz de modo apartado das 
condições cotidianas, por parâmetros instituídos fora da situação vivida.

Essa lógica de pensamento produz perguntas referentes à proteção. Será que punindo as famílias denunciadas teremos todas as respostas, diminuiremos as tensões? Ou no caso do movimento LGBT, será que criando uma lei punitiva fica resolvido o uso livre do corpo? Terminaremos com os preconceitos referentes à pluralidade da sexualidade humana? Como ficam os modos de existência com a presença das leis punitivas?

Toca o telefone. "Eu queria fazer uma denúncia: a minha vizinha deixa o filho dela ser gay". A tal denúncia, recolhida por um estagiário de Psicologia em um conselho tutelar, cabe qual procedimento? Por que um órgão instituído como protetor dos direitos da criança e do adolescente é buscado para atuar em tal questão? Aqui não há transgressão a uma lei, a justiça não pode intervir, mas há uma construção subjetiva judicializante, punitiva, criminalizadora, baseada em um pensamento único sobre a sexualidade. É a vida sendo judicializada em seus espaços de escape, de diferenciação.

O telefone não para de tocar: meu vizinho bate no filho, minha filha está namorando um homem muito mais velho, minha nora é negligente porque deixa o filho com as unhas sujas e o cabelo comprido! São muitas as denúncias dos que se escondem atrás do telefone! Protegido pela denúncia anônima, o denunciante acredita exercer seu direito de cidadão defensor da sociedade. Com tal gesto cria um estado de paz com sua consciência cidadã. A noção de direitos convoca todos a participar e viver segundo seus preceitos, e é a partir dessa noção que se estruturam as relações sociais e a ideia de cidadania - esta, construída em cima da tradicional figura do homem moralizado. O adensamento do direito nas esferas da vida social, tendo em vista a celebração das leis - que cada vez mais são demandadas -, consolida a cultura do julgamento e afirma o chamado cidadão em sua vertente de justiça e segurança, que se sente correto ao atender à demanda de produção de informação, de produção de verdade.

Assim, a denúncia e a vigilância passam a ser desejadas, no intuito de trazer a verdade. Denuncia-se sem qualquer risco, aponta-se uma verdade em uma voz que não é própria, já que há uma lei que conduz o seu enunciado cuja relação com a verdade é construída pela obediência amedrontada. A denúncia anônima é um esconderijo que alimenta o medo, o preconceito, a intolerância, o ressentimento. A estratégia de construir a insegurança generalizada implanta a manipulação dos medos, fazendo com que sejam criados dispositivos protetores, um dos quais é a denúncia. $\mathrm{O}$ sentimento crescente de insegurança contribui largamente para aceitar a visão de uma sociedade na qual a violência está em toda parte e ameaça cotidianamente a estabilidade social.

Chamar, convocar, premiar, incitar as pessoas a denunciar são atitudes que, de algum modo, agenciam aqueles que denunciam as racionalidades das políticas que necessitam de denúncia. A que estão se agenciando os denunciadores fervorosos? À lógica daqueles que dizem estar preocupados com a população? A uma sociedade que forja corpos dóceis? Aos processos de controle biopolítico?

Denuncie, e com isso você estará ajudando a sociedade. Essa convocação, no que se refere à proteção da infância e da adolescência, tem sido feita pelo Governo Federal Brasileiro. Foi com essa chamada que em 2013 ele conclamou a população a participar da campanha nacional de proteção contra o que é anunciado como violência contra essa população. Vídeos, panfletos, matérias de jornal, cartazes anunciavam: "Não desvie o olhar. Fique atento. Denuncie. Proteja nossas crianças e adolescentes". Que verdade está sendo enunciada nesta campanha? A da proteção? A do medo? A do bom cidadão? Se estamos sendo chamados a denunciar é porque há algo a ser denunciado. Todos têm que denunciar algo, mesmo que seja apenas uma suspeita. Essa é uma condição excessivamente presente nos órgãos ditos de proteção: a suspeita. A partir de uma essência do bem, suspeita-se que uma mãe não está tratando adequadamente seu filho. Fazse a denúncia e a família inteira é invadida. Criase uma situação sem controle, porque nesse caso uma denúncia pode ter os efeitos mais variados: vigilância constante da família, suspensão ou destituição do poder familiar, perda da guarda, abrigamento, averiguações, medos, criminalização, incômodos, sofrimentos. Proclama-se uma verdade na voz de um denunciador que não se compromete com os riscos de seu enunciado.

De acordo com Passetti, (2003), "vivemos numa sociedade de controle que se afirma, 
antes de tudo, como sociedade de difusão de direitos" (pp. 31-32). O convite à participação feito à população a coloca em um lugar específico, no dever de garantir os direitos, de ser responsável por eles.

A legislação, ao dizer que a criança e o adolescente são cidadãos de direitos, determina um conjunto de práticas que definem suas relações com o mundo: como devem ser cuidados, escolarizados, preparados para o futuro profissional - enfim, há um jogo contínuo de disciplinamento de condutas. Por meio das leis vão sendo desenhadas forças hegemônicas que exigem participação como forma de existência cidadã. A vinculação de tais proposições com a prática da denúncia é por demais evidente.

\section{É PRECISO DENUNCIAR O RISCO}

Retomar o clássico estudo de Donzelot (1977/1986), "A Polícia das Famílias" inspira o debate sobre risco. Em suas análises sobre o tribunal de menores ele refere a relação entre denúncia e risco: "Isso quer dizer, praticamente, crianças recrutadas não através de processos policiais de detenção mas através dos procedimentos de delação do assinalamento. Um professora, um trabalhador social, um vizinho assinalam ao juiz a existência de uma família 'que corre riscos'”. (p. 103).

Após a emergência do ECA, no campo da infância e da adolescência tudo se faz em nome dessa legislação, parâmetro que passa a regulamentar ações e discursos. Apesar de o Estatuto não referir as palavra risco e vulnerabilidade, não usar a terminologia 'em situação de risco', tais conceitos e suas mecânicas são amplamente utilizados no cotidiano dos espaços de atendimento à população infanto-juvenil pobre, seja na área da educação, da saúde, da assistência ou do judiciário, seja nos conselhos tutelares. A busca de proteção a qualquer custo é uma estratégia de governo que controla a sociedade por dispositivos de segurança e produz a subjetividade 'em risco social'; é um exemplo claro do que Foucault (2004/2008b) chamou de biopoder, em sua determinação de qualificar, medir e esquadrinhar os vivos em torno da norma.

Aqui podemos referir Robert Castel para nos ajudar a pensar o que é risco e como temos vivido sob a constante ameaça de estar em risco. Castel, juntamente com Foucault, é um dos autores que têm possibilitado pensar a proteção como um projeto de segurança que opera pela judicialização. Dois de seus livros são fundamentais para sustentar essa proposição: "A gestão dos riscos" (1981/1987) e "A insegurança social: o que é estar protegido?" (2003/2005). O primeiro, apresenta, entre outros debates, discussões sobre as intervenções médicopsicológicas e suas relações com o aparelho de justiça, esboçando a possibilidade do que chama gestão previsível de perfis humanos. Com isso problematiza a noção de risco e, sobretudo, sua prevenção. No segundo, Castel atualiza esse debate trazendo o que chama de uma aversão social ao risco, que faz com que o indivíduo contemporâneo jamais possa sentir-se totalmente em segurança.

Como são tratadas as situações de risco? Como nem todos os riscos podem ser individualmente administrados, foi se fortalecendo a necessidade premente de um poder social protetor, condição que a partir do século $X X$ levou a enormes investimentos em políticas de segurança por parte do Estado e à organização de parâmetros de proteção contra aquilo que se reconhece como perigo. Como diz Castel (2003/2005), "a 'cultura do risco' fabrica perigos" (p. 62; itálicos do autor). Suas análises estão em parceria com aquelas colocadas por Foucault quando nos fala de modos de funcionamento social que impõem uma crença: aquela que diz que a melhor vida é a que se distancia dos riscos, que é segura, mesmo que se tenha que abrir mão de suas potências, de suas possibilidades. Ambos os autores afirmam que "o controle dos riscos vai assumindo importância fundamental como poder de autovigilância e como mecanismo de interferência nos hábitos das pessoas 'pelo seu próprio bem', 'pela sua própria vida'” (Moraes \& Nascimento, 2002, p. 100).

É visto como um risco, por exemplo, o fato de uma criança viver em uma família que não seja considerada modelar, o que justifica uma intervenção do Estado para protegê-la, negandose-lhe a possibilidade de viver nessa família em favor de abrigamentos muitas vezes tão questionáveis quanto as práticas familiares interditadas. Com isso são instituídas as famílias perigosas, subjetividade que inspira medo, insegurança e, por efeito, a prática de denúncia. $\mathrm{O}$ que o risco permite é modificar o presente por 
uma antecipação do futuro, que é previsto a partir de operações estatísticas, pelas ações do presente.

A estratégia de construir a insegurança generalizada implanta a manipulação dos medos, fazendo com que as pessoas clamem por mais justiça e proteção. A produção de um sentimento crescente de insegurança contribui largamente para aceitar a visão de uma sociedade na qual a violência está em toda a parte e ameaça cotidianamente a estabilidade social. Nesse quadro de configurações a denúncia aparece como um bem, como naturalmente importante e necessária.

\section{A DENÚNCIA E A ORDEM PUNITIVA}

Referindo-se às lettres de cachet, Foucault (1994/2012a) vai nos falar de um poder político sem limites no âmbito das relações cotidianas, por meio da denúncia, da queixa, da espionagem do registro escrito acusatório: “... vozes múltiplas que se depositam em uma enorme massa documental e constituem assim, através dos tempos, como a memória incessantemente crescente de todos os males do mundo" (p. 213).

Talvez acompanhar Foucault nas análises que faz dessas cartas (lettres) nos permita estranhar os telefonemas acusatórios que chegam aos conselhos tutelares, mas antes é preciso aclarar esse instrumento de denúncia pesquisado pelo filósofo. Tais cartas eram documentos com o selo do rei que autorizavam a prisão de alguém tido como de mau comportamento. Tal autorização podia ser solicitada por "maridos ultrajados por suas esposas, pais de família descontentes com seus filhos, famílias que queriam se livrar de um indivíduo, comunidades religiosas perturbadas por alguém, uma comuna descontente com seu cura" (Foucualt, 2006, p. 96). Desse modo, essas cartas funcionavam como um mecanismo de ingerência na vida privada e de controle dos indivíduos, podendo ser entendidas como "uma forma de regulamentar a moralidade cotidiana da vida social, uma maneira do grupo ou dos grupos - familiares, religiosos, paroquiais, regionais, locais, etc. - assegurarem seu próprio policiamento e sua própria ordem (p. 97)".

As cartas produziam prisão, ódios, intrigas e um poder político. Foucault (1994/2012a) nos diz que esses documentos funcionavam por meio do disparate, principalmente o disparate entre “... a ordem minúscula dos problemas levantados e a enormidade do poder aplicado...." (p. 218). Os telefonemas anônimos produzem punição, práticas de justiça e averiguação, e também operam um poder político da ordem do disparate que envolve vinganças, brigas de vizinhos e desavenças familiares que se apegam às minúcias, mas que têm a força de devastar determinadas vidas: a mãe bebe na frente do filho, tirou o filho da escola privada e colocou na pública, deixa os filhos sozinhos em casa quando vai trabalhar. Eis aí um colossal instrumento de disciplinamento dos corpos. Nessa busca da verdade criminosa institui-se a objetivação do outro: são vidas que se tornam casos ao percorrer os espaços de investigação de tais acontecimentos (os conselhos tutelares, por exemplo) e os espaços do judiciário.

Os modos de vida denunciados ganham visibilidade a partir da captura nas malhas das relações de poder dos corpos em seus desvios. Em nome da proteção das crianças e dos adolescentes, em defesa da sociedade, são utilizados pelos órgãos ditos de defesa dos direitos mecanismos, que se reportam sempre às normas de referência para crianças, jovens, família, casal, saúde e proteção, com fins de controle.

Os denunciadores têm como objetivo fazer uso de uma legislação punitiva para regular os cotidianos familiares, ao modo das lettres de cachet na vida dos homens infames. Esse notável exemplo trazido por Foucault funcionou como dispositivo de controle e vigilância durante os séculos XVII e XVIII, tendo sido criado por demanda da própria população, e mais tarde servido de modelo para a institucionalização da prisão e da polícia. Foucault (1994/2012a) refere que as famílias usavam esse dispositivo como controle interno, destinado aos chamados excessos juvenis - como a libertinagem e os escândalos; ou seja, eram utilizadas como instrumentos para assegurar a ordem. Do mesmo modo, as denúncias clamam por justiça e se justificam pela busca da vida certa.

A institucionalização da denúncia é produzida por vetores que com sua força compõem novas relações. Cabe então nos perguntarmos: que forças estão presentes na prática da denúncia? Uma delas é a produção de individualização. O risco é sempre atrelado ao comportamento de cada um - portanto o processo de culpabilização e de acusação se faz 
pela redução do outro à condição de objeto a ser denunciado, seguindo um vetor de individualização. O denunciador visa acusar um indivíduo, e para tanto encontra nele o desvio em relação a um modelo, criando um campo fechado, linear, e configurando uma identidade como, por exemplo, a da mãe negligente, ou a da família em desordem. Para Guattari (Guattari \& Rolnik, 2010) o processo de individualização cria práticas serializadas, moldadas por padrões universais e massificadores. Para o autor, o processo de individualização, modo predominante de produção de subjetividade, se faz quando são assimilados modos de ser e viver homogêneos, tidos como corretos e verdadeiros. O escape a esse modelo é visto como algo da ordem do desviante e, por esse viés, torna-se justificável uma intervenção, por exemplo, por meio da denúncia.

A prática da denúncia não considera as diferentes forças presentes no mundo, que se constituem por continuidade e inacabamento. Atua por processos de individualização que criam seus próprios mundos, com subjetividades específicas tomadas como se fossem válidas para qualquer tempo e lugar. Desse modo, são estabelecidas forças que fazem a palavra legal funcionar de modo a prescrever comportamentos.

Acreditamos que a denúncia suscita uma série de questões ligadas à maneira de se intervir nas chamadas situações de violação dos direitos de crianças e adolescentes. Observamos de modo incisivo práticas de julgamento, punição e ameaça sendo exercidas sobre modos de vida diferenciados, que se impõem com a prática da conclamação da lei e da subsequente denúncia. Disso podemos inferir que tais práticas contribuem para responsabilizar determinados segmentos da população e desmobilizar o potencial coletivo das relações sociais.

\section{REFERÊNCIAS}

Brasil, (1988) Constituição da República Federativa do Brasil de 1988.

Castel, R. (1987). A gestão dos riscos: da antipsiquiatria à póspsicanálise. (C. Luz, Trad.). Rio de Janeiro: Francisco Alves. (Original publicado em 1981).

Castel, R. (2005). A insegurança social: o que é ser protegido? (L. M. Endlich, Trad.). Petrópolis, RJ: Vozes. (Original publicado em 2003).

Donzelot, J. (1986). A polícia das famílias. (M. T. Albuquerque, Trad.). Rio de Janeiro: Graal. (Original publicado em 1977).

Foucault, M. (1988). História da Sexualidade I: a vontade de saber. (M. T. C. Albuquerque \& J. A. G. Albuquerque, Trads.). Rio de Janeiro: Graal. (Original publicado em 1976).

Foucault, M. (2008a). Segurança, território e população. (E. Brandão, Trad.) São Paulo: Martins Fontes. (Original publicado em 2004).

Foucault, M. (2008b). Nascimento da biopolítica. (E. Brandão, Trad.). São Paulo: Martins Fontes. (Original publicado em 2004).

Foucault, M. (2010). Em defesa da sociedade.(M.E. Galvão, Trad.). São Paulo: Martins Fontes. (Original publicado em 1997).

Foucault, M. (2012a) A vida dos homens infames. In M. Foucault. Ditos e escritos IV (pp. 203-222). (V. L. A. Ribeiro, Trad.). Rio de Janeiro: Forense Universitária. (Original publicado em 1994).

Foucault, M. (2012b). A estratégia do contorno. In M. Foucault. Ditos e escritos VIII (pp. 133-136). (V. L. A. Ribeiro, Trad.). Rio de Janeiro: Forense Universitária. (Original publicado em 1994).

Guattari, F., \& Rolnik, S. (2010). Micropolítica: Cartografia do desejo, Petrópolis, RJ: Vozes.

Moraes, T. D., \& Nascimento, M. L. (2002). Da norma ao risco: transformações na produção de subjetividades contemporâneas. Psicologia em Estudo, 7(1), 91-102.

Passetti, E. (2003). Anarquismos e sociedade de controle. São Paulo: Cortez.

Recebido em 22/11/2013

Aceito em 01/10/2014

Maria Livia do Nascimento: professora titular do Departamento de Psicologia e do Programa de Pós-Graduação em Psicologia da Universidade Federal Fluminense, Brasil. 